\title{
A PELEJA DE JOÃO AMARO: um trabalhador rural na luta por direitos (Pernambuco, anos 1960)
}

\author{
Márcio Ananias Ferreira Vilela* \\ Marcelo Góes Tavares**
}

\begin{abstract}
RESUMO: Este artigo analisa a experiência de um trabalhador rural que em 1965 recorreu à Justiça do Trabalho em Pernambuco para reivindicar a efetivação de direitos já previstos em lei. Também analisamos como os proprietários das usinas de cana-de-açúcar faziam uso de inúmeros mecanismos para burlar a legislação trabalhista, inclusive nomeando trabalhadores como agitadores e subversivos. Nesses casos, tentava-se representar tais trabalhadores rurais como sujeitos comunistas e perigosos, o que poderia desqualificar suas demandas por direitos na Justiça do Trabalho. Ou ainda produzir maiores implicações aos acusados quando considerado o regime civil e militar no Brasil, podendo os trabalhadores serem presos e torturados, e em alguns casos, até mortos pelos órgãos de segurança e informação. Analisa-se desse modo, o funcionamento da Justiça do Trabalho e a trama na qual os litigantes estão inseridos nas lutas políticas e por direitos. Como fonte documental para análise, utilizamos um processo trabalhista, que compõe o acervo da Justiça do Trabalho na Universidade Federal de Pernambuco.
\end{abstract}

PALAVRAS-CHAVE: História; Trabalho; Direitos; Justiça do trabalho.

\section{The fight of João Amaro: a rural worker in fight for rights (Pernambuco, years 1960)}

ABSTRACT: This article analyzes the experience of a rural worker who in 1965 appealed to the Labor Court in Pernambuco to claim the enforcement of rights already provided by law. We also analyze how the owners of the sugarcane mills made use of numerous mechanisms to circumvent labor laws, including appointing workers as agitators and subversives. In these cases, attempts were made to represent such rural workers as communist and dangerous subjects, which could disqualify their demands for rights in the Labor Court. Or it may have greater implications for the accused when considering the civil and military regime in Brazil, and the workers may be arrested and tortured, and in some cases even killed by the security and information agencies. In this way, the functioning of the Labor Court is defined and the plot in which the litigants are inserted in the political and rights struggles. As a documentary source for analysis, a labor process which compiles the collection of Labor Justice at the Federal University of Pernambuco.

KEYWORDS: History; Labor; Rights; Labor Justice.

\section{La pelea de João Amaro: un trabajador rural en la lucha por derechos (Pernambuco, años 1960)}

Resumen: Este artículo analiza la experiencia de un trabajador rural que en 1965 recurrió a la Justicia del Trabajo en Pernambuco para reivindicar el cumplimiento de derechos ya garantizados en la ley. También analizamos cómo los propietarios de la fábrica de azúcar usaban innumerables mecanismos para burlar la legislación laboral, incluso acusando los trabajadores como agitadores y subversivos. En esos casos, se intentaba representar a tales trabajadores rurales como sujetos comunistas y peligrosos, lo que podría descalificar sus demandas por derechos en la Justicia del Trabajo, o incluso producir mayores implicaciones a los acusados cuando se considera el régimen civil y militar en Brasil, pudiendo los trabajadores ser presos y torturados, y en algunos casos, hasta muertos por los órganos de seguridad e información. Se analiza de ese modo, el funcionamiento de la Justicia del Trabajo y la trama en la cual los litigantes se insertan en las luchas políticas y por derechos. Como fuente documental para análisis, utilizamos un proceso laboral que compone el acervo de la Justicia del Trabajo en la Universidad Federal de Pernambuco.

Palabras clave: Historia, Trabajo, Derechos, Justicia laboral.

\footnotetext{
* Doutor pelo Programa de Pós-Graduação em História da Universidade Federal de Pernambuco. Atualmente, é professor de História no Colégio de Aplicação da UFPE. Contato: ananiasvilela @ hotmail.com.

** Doutor pelo Programa de Pós-Graduação em História pela Universidade Federal de Pernambuco. Atualmente é professor de História do Brasil na Universidade Estadual de Alagoas - Campus Palmeira dos Índios. Contato: Rod. Eduardo Alves da Silva, Km 3, Graciliano Ramos, CEP: 57604-595, Palmeira dos Índios - AL. E-mail: marce_goes@hotmail.com.
} 


\section{A trama: trabalhadores rurais entre a luta por direitos e as possibilidades de subversão}

No dia 17 de agosto de 1965 foi protocolada na Junta de Conciliação e Julgamento JCJ de Paulista, sob o $n^{\circ}$ 0631/65, uma ação contra a Usina São José S/A, localizada no município de Igarassu, na Mata Norte de Pernambuco, município que atualmente faz parte da região metropolitana do Recife. Na petição inicial, o trabalhador rural João Amaro de Lima, que morava e exercia suas atividades laborais no Engenho Mussupinho, de propriedade da referida Usina, reclamou sua reintegração ao trabalho, férias que nunca tinham sido concedidas a ele, salários vencidos e vincendos, e juros sobre os valores que lhe eram devidos pelo patrão.

O trabalhador reclamante afirmava haver sido admitido para trabalhar nas terras do engenho pertencente à Usina no mês de junho de 1954 e que desde então havia exercido suas inúmeras atividades de maneira ininterrupta até outubro de 1964 quando, sem que lhe fosse apresentado qualquer tipo de justificativa, fora demitido. E por isso mesmo recorreu à Justiça do Trabalho informando que durante todo o citado período executou atividades no Engenho Mussupinho sob o comando de vários administradores e que, no momento da sua demissão, recebera um salário de $\mathrm{Cr} \$ 1.100,00$ (um mil e cem cruzeiros) por dia. Relata ainda que, nos referidos 10 anos como funcionário contratado pela Usina, não gozou férias e, ainda, que ao ser demitido, teria deixado de receber por duas semanas de trabalho.

João Amaro de Lima lutava contra essa situação. Era um trabalhador que se enquadrava na condição de "estabilidade", considerando-se a Consolidação das Leis do Trabalho - CLT (Decreto Lei $n^{\circ} 5.452$ de 01 de Maio de 1943). Segundo seu artigo de ${ }^{\circ} 492$, "o empregado que contar mais de 10 (dez) anos de serviço na mesma empresa não poderá ser despedido senão por motivo de falta grave ou circunstância de força maior, devidamente comprovadas". Já em seu Parágrafo único reforça essa condição ao esclarecer que: "Considera-se como de serviço todo o tempo em que o empregado esteja à disposição do empregador". O trabalhador rural reclamante no processo possuía duradouro vínculo empregatício com a Usina, mais de 10 anos, o que lhe garantia como direito, a estabilidade. Situação que poderia tornar ilegal a demissão sem justa causa. Como estratégia, a Usina irá justificar sua demissão considerando a conduta de João Amaro durante alguns expedientes, acusando-o de abandono de suas atividades laborais.

Esse tipo de reclamação movida por João Amaro de Lima era uma demanda comum, assim como a alegação da Usina, aparecendo em muitos processos, entre outros, não só nas JCJ's de Pernambuco, mas também de outros estados. Fato que sugere um notório desrespeito 
por parte de patrões ao que era determinado como direito para os trabalhadores, prática corriqueira e de violência quando investigamos historicamente o trabalho rural no Brasil.

A violência em suas múltiplas formas é posta em relação com a miséria, inclusive, foram bastante naturalizadas em Pernambuco durante a década de 1960, sobretudo pela imprensa, como sinaliza o historiador Pablo Porfírio no livro Medo, comunismo e revolução: Pernambuco (1959-1964). Essa relação, para o autor, apresenta-se como uma questão central na medida em que a miséria do camponês tornava-se componente potencializador de uma situação de produção de periculosidade por trabalhadores, inclusive de ameaça à ordem vigente.

Alguns jornais do Brasil e de Pernambuco enfatizavam cotidianamente o perigo representado pelos camponeses, seja porque esses passaram a reivindicar mudanças sociais consideradas subversivas, principalmente, por meio das ocupações dos engenhos, seja porque esses trabalhadores eram inocentes e facilmente poderiam ser manipulados pelos denominados agitadores, isto é, pessoas ligadas ao comunismo. (PABLO, 2009, p. 74).

As tensões entre trabalhadores e patrões entre 1943 e 1964 eram constantes. Em grande medida, essas também eram insufladas pelo cenário político, econômico e social brasileiro durante o período democrático (1945-1964). Momento de múltiplas e simultâneas experiências sociais, a exemplo do exercício de governos trabalhistas, da atuação de comunistas, da crescente industrialização, de ocorrências de greves, de mobilizações de lutas pela ampliação de direitos sociais, da organização sindical, da expressiva participação política e protagonismo dos trabalhadores, de reação de grupos conservadores e de direita reprimindo trabalhadores ou mesmo ameaçando a legalidade constitucional com a constante iminência de golpe de Estado.

Nesse cenário, a Justiça do Trabalho e as próprias Juntas de Conciliação e Julgamento JCJ's, atuavam em litígios movidos por diversas razões de ambos os lados, trabalhadores e patrões. Tendo como foco central as relações de trabalho, as JCJ's atuavam em rescisões contratuais de trabalho por questões produtivas e/ou políticas, reparação para situações de exploração do trabalhador e condições inadequadas no ambiente de trabalho, combate à disseminação de ideias comunistas e prejudiciais aos interesses capitalistas, licença maternidade, abono natalino ( $13^{\circ}$ salário), autorização de demissão de trabalhadores por justa causa, entre outras diversas.

No entanto, em grande medida essa atuação da Justiça do Trabalho era restrita ao âmbito urbano. A Consolidação das Leis do Trabalho não se estendia aos trabalhadores rurais. 
Situação que se modificou em 1963 quando o então Presidente João Goulart sancionou a Lei

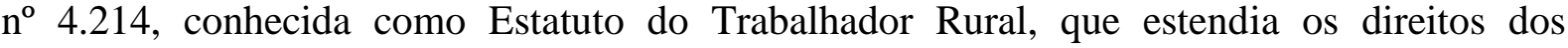
trabalhadores urbanos para os trabalhadores rurais. E que João Amaro de Lima, mesmo tendo sido contratado pela Usina em 1954, teria sido beneficiado pela mudança nas leis do trabalho. O que não significou transformações substanciais nas relações de trabalho no campo.

No ano de 1964, havia sido instalado, através de golpe de Estado com participação militar e civil, um regime de exceção, implantando uma ditadura no país. O golpe de 1964 representou uma reação repressora e refreadora nos avanços da cidadania e dos direitos sociais, em especial de trabalhadores.

$\mathrm{Na}$ medida em que as reivindicações sociais dos trabalhadores eram apresentadas como ações comunistas e uma ameaça à sociedade, é plausível considerar a possibilidade de que inúmeros trabalhadores rurais ao fazerem uso da Justiça do Trabalho passaram a ser qualificados pelos patrões, imprensa, e forças repressivas, como subversivos ou a serviço do comunismo.

Ou mesmo, como destaca o historiador Antonio Torres Montenegro sobre esse período e respectivas práticas:

\footnotetext{
Lutar por direitos, especialmente trabalhistas, se constituirá em sinônimo de subversão da ordem e comunismo, como atestam os documentos da polícia e dos diversos órgãos militares e de informação do governo [...]. Logo, os trabalhadores nomeados e reconhecidos como comunistas se tornaram alvo de perseguições e prisões arbitrárias. (MONTENEGRO, 2011, p. 233).
}

Ora, é exatamente na perspectiva dos trabalhadores serem vistos como associados ao comunismo que desejamos compreender os embates registrados nesse processo. $\mathrm{O}$ que significava acusar os trabalhadores de comunistas, sobretudo no período em que o Brasil vivenciava uma ditadura civil e militar? ${ }^{1}$ Como tal acusação poderia interferir no julgamento das demandas dos trabalhadores?

\section{João Amaro: na luta por direitos, contra as acusações de subversão}

Sobre o acesso de trabalhadores à Justiça, a historiadora Christine Rufino Dabat realizou estudos ${ }^{2}$ bastante detalhados acerca dos processos movidos por trabalhadores rurais nas três primeiras JCJ's criadas em cidades do interior do estado de Pernambuco (Jaboatão, Escada e Palmares) em 1962, embora estas só tenham efetivamente passado a operar em 1963 com a criação do Estatuto do Trabalhador Rural, estendendo os direitos trabalhistas aos 
trabalhadores rurais. $\mathrm{O}$ que não significava que as reinvindicações trabalhistas de camponeses eram inexistentes. Christine R. Dabat destaca que em face da crescente organização dos trabalhadores rurais, principalmente os do setor canavieiro, desde a metade da década de 1950 estes já reivindicavam na justiça comum seus direitos enquanto assalariados. Porém só com o Estatuto do Trabalhador Rural e o efetivo funcionamento das primeiras JCJ's, assim como o avanço da sindicalização e da mobilização realizada pelas Ligas Camponesas, constata-se como a luta por direitos trabalhistas tornou-se uma prática, inclusive se ampliando mesmo após o golpe de 1964.

Como trabalhadores protagonistas que lutavam por direitos, João Amaro acionou a Justiça do Trabalho em 17 de agosto de 1965. Sua primeira audiência foi realizada no dia 22 de setembro do mesmo ano, e presidida pelo juiz suplente Otacílio Dantas Cartaxo. A defesa da Usina São José S/A foi conduzida pelo advogado Walfrido Uchoa Cavalcanti, que, ao contestar a reclamação, alegou:

O reclamante trabalhou para a reclamada até os princípios do ano de 1964, quando por motivos de agitação sindicalista revoltou-se no trabalho e cortou com a foice os pneumáticos do trator pertencente à reclamada, e sendo o caso levado ao conhecimento da polícia o reclamante fugiu e abandonou o serviço. ${ }^{3}$

É relevante salientar que acusar alguém em tal momento de agitação sindical possivelmente poderia produzir inúmeras implicações, como a abertura de investigações, prisões e quem sabe até tortura e morte. Era uma acusação que tinha por intuito desqualificar o trabalhador, colocando-o sob suspeita, permitindo questionar sobre a validade e legitimidade dos direitos trabalhistas que pleiteava na Justiça do Trabalho. Entre uma e outra alegação de defesa, o representante da Usina prosseguia com as tentativas de desqualificar as demandas apresentadas na petição inicial pelo trabalhador. Informou que o senhor João Amaro teria passado mais de um mês sem comparecer ao trabalho. Nem sequer teria apresentado qualquer justificativa, motivo pelo qual havia se dado a sua automática demissão.

Essa era uma estratégia bastante operacionalizada pelos patrões, de modo que a Usina se apresentava como cumpridora da lei e ao mesmo tempo responsabilizava o próprio trabalhador por sua demissão. Na sequência dos fatos foi esclarecido pelo advogado Walfrido Uchoa Cavalcanti à JCJ que a Usina São José não reconhecia o tempo de serviço alegado pelo trabalhador, considerando que sua contratação apenas havia sido efetivada em novembro de 1961. Além disso, argumentaram que João Amaro era bastante ausente do trabalho, tendo sido contabilizadas inúmeras faltas em sua ficha funcional, o que o impossibilitava de completar 
um período que lhe assegurasse o direito ao benefício das férias. Nesses termos, a possibilidade de conciliação na JCJ era afastada pela Usina.

Em sua defesa, João Amaro de Lima reafirmou as alegações presentes na petição inicial e também passou a questionar as acusações a ele dirigidas, entre as quais a de participar em quaisquer movimentos considerados como subversivos à época. Assim, nesta mesma Ata de 17 de agosto de 1965, foi registrado o interrogatório do reclamante da seguinte forma:

[...] que em 1954 o depoente tinha 12 anos; que recebia salário de maior toda vida; que recebia o salário de $\mathrm{Cr} \$ 1.100$, diário; que o depoente foi posto fora do trabalho sob a falsa acusação de ter rasgado os pneus de um trator; que o depoente foi preso inocente; que foi preso pelo vigia Moacir e levado para a Usina; que foi preso dentro de um quarto dois dias e meio e depois solto; que descontaram o preço do pneu no salário e recebeu Cr\$ 300 de saldo de duas semanas de trabalho; que o depoente não respondeu inquérito policial; que o depoente não fugiu, uma vez que não era autor do crime; que tem um primo que tem o nome também parecido com o depoente; que não fazia parte da Ligas Camponesas e não fazia parte também do Sindicato Rural. ${ }^{4}$

$\mathrm{Na}$ defesa realizada pela Usina, ficou registrado que a polícia teria sido informada sobre o suposto crime cometido por João Amaro, ou seja, que o trabalhador teria cortado os pneus de um trator. No depoimento do trabalhador, essa informação não foi confirmada. Pelo contrário, João Amaro, em seu depoimento, tentando produzir um sentido de injustiça que teria sido realizada contra ele, justificando sua ação e pleito na Justiça do Trabalho, informou que não fora levado à delegacia para prestar esclarecimentos à autoridade policial sobre o ocorrido. Foi preso por uma espécie de capanga, e mantido preso nas dependências da própria Usina. Ou seja, torna plausível que no mundo rural à época, em especial no setor canavieiro, poderiam existir milícias mantidas pelos próprios usineiros e latifundiários, de modo que estes ensejassem a realização de sua própria justiça em face de seu poder e interesses. Ao mesmo tempo, permite-nos reconhecer práticas de um poder arcaico, que remete ao Brasil rural das primeiras décadas do século $\mathrm{XX}$, a exemplo do coronelismo, porém atualizadas nesse presente. Destaca-se também o esforço do trabalhador no sentido de desvincular-se de qualquer movimento, seja do Sindical Rural ou das Ligas Camponesas, então considerados como subversivos. Com o golpe civil-militar de 1964, instituindo um regime de exceção no Brasil, tais movimentos sofreram profunda desmobilização com a prisão, tortura e morte de muitos camponeses (MONTENEGRO, 2011).

O trabalhador João Amaro de Lima procurou se desvencilhar de qualquer acusação esclarecendo existir outro trabalhador, um primo, cujo nome poderia ter sido confundido com o seu, fazendo uso naquela ocasião de uma tática, de uma trampolinagem. Como afirma 
Michel de Certeau, "a tática, verdadeira prestidigitação, se introduz por surpresa numa ordem. A arte de "dar um golpe"”. (CERTEAU, 1994, p. 101). Ora, o que desejava João Amaro ao expor a existência de um primo cujo nome era Luiz Amaro de Lima? Lançar dúvidas sobre tais acusações ou indicar que seu primo poderia estar envolvido com movimentos subversivos, assim como ter cortado os pneus do trator? Não sabemos ao certo. O que podemos afirmar é que Luiz Amaro de Lima residia no mesmo engenho e havia recorrido à Junta de Conciliação e Julgamento de Paulista também em 17 agosto de 1965. Aliás, as petições iniciais são semelhantes. Em seu processo, o de $n^{\circ}$ 0632/65, não localizamos quaisquer referências sobre sua atuação política ou mesmo se realmente teria sido autor de crime praticado contra o patrimônio da referida Usina.

Em relação ao processo de João Amaro as partes voltaram a se enfrentar aos 21 de outubro de 1965, desta feita com a presença de testemunhas ligadas ao reclamante. Nessa fase a Usina não apresentou testemunhas, aspecto que foi usado para desqualificar o processo quando da impetração de recurso junto ao Tribunal Regional do Trabalho da $6^{\text {a }}$ Região. A primeira testemunha, segundo consta em Ata, afirmou que:

[...] não ouviu dizer que o reclamante fosse um agitador comunista nem tivesse cortado os pneus de um trator[...] que o reclamante era um trabalhador assíduo; que não era membro do Sindicato, nem das Ligas Camponesas, nem agitador; que o reclamante passou 2 dias preso; que essa prisão foi feita pelo administrador de nome Moacir batista; que a dita prisão foi pelo motivo de ter reclamante furado os pneus de um trator; que o reclamante foi preso sem provas; que o depoente não pertenceu ao Sindicato nem andou foragido por ocasião do Movimento de 31 de março $[\ldots]^{5}$.

A segunda testemunha trilhou o mesmo caminho afirmando "que não consta ao depoente que o reclamante fosse agitador comunista; que o depoente não era agitador sindical". ${ }^{6}$ Podemos afirmar que as testemunhas de fato cumpriram o seu papel ao inocentar João Amaro, além de reforçar que a prisão do reclamante acontecera por um funcionário da Usina São José S/A, e não por autoridade policial ou outro representante do Estado.

Mas há também uma preocupação por parte das testemunhas de se desvincularem de quaisquer movimentos considerados subversivos na época, a exemplo das Ligas Camponesas que atuaram sobretudo em Pernambuco e Paraíba até 1964. Não ser foragido no dia 31 de março de 1964, dia do golpe-civil militar, poderia representar a inocência contra acusação de subversão, estando fora da lista de pessoas procuradas e presas pelas forças repressoras do regime que se instalara naquele dia. $\mathrm{O}$ que indica ter sido uma preocupação relevante entre esses trabalhadores. Em muitos casos tinham que lutar para escapar de acusações de cunho 
político que poderiam incidir na perda de direitos. Desse modo, podemos perceber o quanto também as fronteiras entre os campos políticos e jurídicos poderiam estar em relação intrínseca nos embates envolvendo trabalhadores e patrões.

O que haveria acontecido a João Amaro? Suas demandas foram atendidas mesmo diante de tais acusações pela Usina? Entre idas e vindas na Justiça do Trabalho, aos 30 de novembro de 1965 foi proferida em primeira instância uma decisão favorável ao trabalhador, sendo atendidas as suas demandas como apresentadas na petição inicial. Afirma a sentença, "que as alegações de que o reclamante foi preso pelo vigia, porque cortara um pneu do trator, e também que o mesmo seja agitador pertencente as Ligas Camponesas, não foi provado pela reclamada". 7

Em alguns casos estudados pelo historiador Antonio Torres Montenegro ${ }^{8}$, os juízes do trabalho solicitavam diligências externas à Polícia Civil e ao Exército para apurar denúncias de atividades subversivas contra os trabalhadores. Tais informações poderiam complementar e até mesmo ensejar modificações nas decisões judiciais. Assim, juízes das Juntas de Conciliação e Julgamentos algumas vezes acatavam os argumentos dos advogados das empresas/patrões de que o(s) reclamante(s) (trabalhador ou grupo de trabalhadores) faziam reuniões e veiculavam ideias consideradas subversivas à ordem. Em outros casos, quando não se comprovava a acusação e denúncia, a decisão poderia ser favorável ao trabalhador.

No caso de João Amaro, na primeira instância da Justiça do Trabalho, no âmbito da Junta de Conciliação e Julgamento, foi preponderante a preocupação dos juízes sobre a posição política do trabalhador, não o considerando agitador, comunista ou mesmo integrante das Ligas Camponesas. Isso nos leva a pensar em outras possibilidades: que sendo constatado ser João Amaro comunista ou membro das Ligas Camponesas, a JCJ poderia ter negado sua demanda por direito e justiça.

\section{Considerações finais}

Podemos inferir que o tipo de acusação evidenciado no processo de João Amaro de Lima foi utilizado para desqualificar politicamente pessoas, considerando-as subversivas quando contestavam o status quo político e social, principalmente após o golpe civil e militar de 1964. Assim, a acusação de comunista figurou no processo trabalhista com o objetivo de atenuar ou anular os direitos do reclamante assegurados na legislação trabalhista vigente. 
Do mesmo modo, o acesso de um número cada vez mais crescente de trabalhadores rurais a Justiça do Trabalho tem sido apresentado por setores da historiografia como um ganho real dos trabalhadores. A historiadora Angela de Castro Gomes afirma que a instituição dos diversos direitos trabalhistas e depois a sua consolidação em 1943 não pode ser analisada como uma simples ação populista do presidente-ditador Getúlio Vargas. São direitos que representavam anos de luta e a vitória dos trabalhadores, significando ganhos importantes (GOMES, 2002).

É necessário salientar que entre o texto da lei e a operacionalização por seus operadores nas diferentes instâncias da Justiça existem movimentos e posições que devem ser considerados. O fácil acesso à Justiça pelo trabalhador não implica no fato de que todas as reclamações contra patrões sejam atendidas. E da mesma forma, a existência da lei e condições efetivas de direitos, não representa a efetividade de ambos. É preciso pensar a Justiça como instância de poder que embora seja definida por regras e normas, seus movimentos (dos processos, dos operadores do Direito, dos litigantes, das testemunhas, e dos próprios agentes do Estado que lhe dão suporte) nem sempre são bem definidos, ou quando são, não seguem necessariamente uma ordem lógica conforme os interesses e idealizações dos trabalhadores. Ao contrário, abrem-se ao revés em seus usos - jurídicos, sociais, e políticos -, tornando-se um mundo aparentemente estranho. E a própria idealização Justiça do Trabalho como instância paternalista e de proteção dos trabalhadores é desnaturalizada, possibilitando outras leituras sobre seus usos políticos e de poder.

E embora João Amaro de Lima, na primeira instância (JCJ) tenha sido inocentado das acusações que recaía sobre ele, legitimando os direitos que reclamava, aos 19 de janeiro de 1966 o Parecer da Procuradoria Regional do Trabalho da $6^{a}$ Região deu por rejeitada a decisão da Junta de Conciliação e Julgamento de Paulista. Acatou o recurso de que teria existido o cerceamento da defesa. A documentação indica que o Parecer foi encaminhado para apreciação do Tribunal, no entanto a publicação do Acórdão não foi realizada, ou mais precisamente, não costa no corpo do processo JCJ $n^{\circ}$ 0631/65.

O final desse enredo é incerto, como incerta era a própria Justiça do Trabalho, ou qualquer outro campo da Justiça. O que nos lembra a situação de outro personagem, este ficcional, na obra "O processo" de Franz Kafka. Trata-se de Josef K e sua insistente luta por absolvição durante um processo que nem sequer teve acesso à acusação que lhe era imputado (KAFKA, 2005). Assim como Josef K., o trabalhador João Amaro de Lima foi envolvido em um terreno movediço das instituições do Estado, de poder, no qual sua luta por direito, ao 
revés, também se tornou uma peleja contra a acusação por parte da Usina. E quanto ao desfecho do processo? Deixamos a cabo da imaginação dos leitores... O que também nos permite concebê-la como uma história em aberto, com outras lições sobre essa peleja.

E para além dos direitos trabalhistas, como relevante campo de interesse historiográfico, destacamos ainda a própria trajetória do trabalhador reclamante, João, um operário do açúcar que trabalhava em um engenho pertencente a uma Usina cuja razão social leva o nome do santo protetor dos operários - o São José. Um revés aos interesses de trabalhadores, uma ironia, senão azar também comum no universo rural no Brasil. A Usina São José S/A, para quem João prestava serviço, poderia ser aquilo que outro operário, anos depois, designou para a Usina Catende, também no estado de Pernambuco, a imagem do "vapor do diabo"". Como lócus do diabo cuja morada é o inferno, os engenhos, as lavouras de cana-de-açúcar e as usinas eram locais laborais, entre outros, que exauriam forças e saúde, sonhos e desejos, direitos e cidadania, tornando-se realidade plausível em trajetórias de centenas de outros Joãos-trabalhadores pelo Brasil. Trajetórias marcadas pela condição de miséria e precariedade de toda sorte, do trabalho, da moradia, da alimentação, da restrição de direitos, e que atingiam os trabalhadores não somente em vida, mas também na morte, quando estes muitas vezes também se tornavam desprovidos de um caixão para seus enterros tamanha eram suas pobrezas. Ou mesmo o silenciamento das memórias de suas lutas, que pode também se tornar o apagamento das suas existências e respectivos legados para a contemporaneidade.

\section{Notas}

\footnotetext{
${ }^{1}$ Existe uma consolidada historiografia que analisa a derrubada do presidente João Goulart como um golpe civil e militar, dada a significativa participação de setores da sociedade legitimando tais ações. Historiadores como Daniel Aarão Reis, Ângela de Castro Gomes e Jorge Ferreira, dentre outros, também entendem o governo implantado a partir de 1964 como um Regime civil e militar, dado os seus contornos legais e a intensa integração das instituições civis ao governo.

2 Ver DABAT, Christine Rufino. "Uma caminhada 'penosa': A extensão do Direito trabalhista à zona canavieira de Pernambuco". CLIO. Série Revista de Pesquisa Histórica. Recife: Editora da UFPE, n. 26-2. 2008. Ver também, DABAT, Christine Rufino. Moradores de engenho. Relações de trabalho e condições de vida dos trabalhadores rurais na zona canavieira de Pernambuco, segundo a literatura, a academia e os próprios atores sociais. Recife: Editora Universitária UFPE, 2007.

${ }^{3}$ Ata de instrução e julgamento da reclamação no $631 / 65$ realizada em audiência de 22 de setembro de 1965. In: JUSTIÇA DO TRABALHO / JUNTA DE CONCILIAÇÃO E JULGAMENTO DO PAULISTA. Processo Trabalhista da Junta de Conciliação e Julgamento do Paulista, $n^{\circ}$ 0631/65, p. 12. (Acervo do Arquivo do TRT/UFPE).

${ }^{4}$ Ata de instrução e julgamento da reclamação no631/65 realizada em audiência de 22 de setembro de 1965 . In: JUSTIÇA DO TRABALHO / JUNTA DE CONCILIAÇÃO E JULGAMENTO DO PAULISTA. Processo
} 
Trabalhista da Junta de Conciliação e Julgamento do Paulista, $n^{\circ} 0631 / 65$, p. 13. (Acervo do Arquivo do TRT/UFPE).

${ }^{5}$ JUSTIÇA DO TRABALHO / JUNTA DE CONCILIAÇÃO E JULGAMENTO DO PAULISTA. Processo Trabalhista da Junta de Conciliação e Julgamento do Paulista, $n^{\circ}$ 0631/65, p. 14. (Acervo do Arquivo do TRT/UFPE).

${ }^{6}$ JUSTIÇA DO TRABALHO / JUNTA DE CONCILIAÇÃO E JULGAMENTO DO PAULISTA. Processo Trabalhista da Junta de Conciliação e Julgamento do Paulista, $n^{o}$ 0631/65, p. 15. (Acervo do Arquivo do TRT/UFPE).

7 JUSTIÇA DO TRABALHO / JUNTA DE CONCILIAÇÃO E JULGAMENTO DO PAULISTA. Processo Trabalhista da Junta de Conciliação e Julgamento do Paulista, $n^{\circ}$ 0631/65, p. 24. (Acervo do Arquivo do TRT/UFPE).

8 Ver MONTENEGRO, Antonio Torres. Agitação política e direito trabalhista nos idos de 1964. In: MONTENEGRO, Antonio Torres; GUIMARÃES NETO, Regina Beatriz; ACIOLI, Vera Lúcia (Orgs.). História, cultura, trabalho: questões da contemporaneidade. Recife: Ed. Universitária da UFPE, 2011. Ver também MONTENEGRO, Antonio Torres. Ação trabalhista, repressão policial e assassinato em tempo de regime militar. IN: REVISTA TOPOI v. 12, n. 22, jan.-jun. 2011, p. 228-249.

${ }^{9}$ Essa representação para a Usina Catende foi produzida por um operário do açúcar entrevistado por José Sérgio Leite Lopes, durante pesquisa em 1972 para sua dissertação de mestrado em Antropologia Social. Esta, posteriormente foi publicada sob formato de livro. Ver: LOPES, José Sergio Leite. O Vapor do Diabo. $O$ trabalho dos operários do açúcar. Rio de Janeiro: Paz e Terra, 1978.

\section{Referências Bibliográficas}

CERTEAU, Michel de. A invenção do cotidiano. V. 1. Artes de fazer. Petrópolis, RJ: Vozes, 1994.

DABAT, Christine Rufino. "Uma caminhada 'penosa': A extensão do Direito trabalhista à zona canavieira de Pernambuco”. CLIO. Série Revista de Pesquisa Histórica. Recife: Editora da UFPE, n. 26-2. 2008.

Christine Rufino. Moradores de engenho. Relações de trabalho e condições de vida dos trabalhadores rurais na zona canavieira de Pernambuco, segundo a literatura, a academia e os próprios atores sociais. Recife: Editora Universitária UFPE, 2007.

GOMES, Angela de Castro. Cidadania e direitos do trabalho. Rio de Janeiro: Jorge Zahar Ed., 2002.

GÓES. Marcelo Tavares (Org.). Nas travessias do tempo: histórias de protagonismos, resistências e lutas políticas. Maceió: Edufal, 2017.

LOPES, José Sergio Leite. O Vapor do Diabo. O trabalho dos operários do açúcar. Rio de Janeiro: Paz e Terra, 1978.

MONTENEGRO, Antonio Torres. Ação trabalhista, repressão policial e assassinato em tempo de regime militar. In: Revista Topoi, v. 12, n. 22, jan.-jun. 2011.

Antonio Torres. Agitação política e direito trabalhista nos idos de 1964. In: MONTENEGRO, Antonio Torres; GUIMARÃES NETO, Regina Beatriz; ACIOLI, Vera Lúcia (Orgs.). História, cultura, trabalho: questões da contemporaneidade. Recife: Ed. Universitária da UFPE, 2011.

PORFÍRIO, Pablo F. de A. Medo, comunismo e revolução. Pernambuco (1959-1964). Recife: EdUFPE, 2009.

KAFKA, Franz. O processo. São Paulo: Companhia das Letras, 2015. 
VILELA, Márcio Ananias Ferreira. Discursos e práticas da Igreja Presbiteriana do Brasil durante as décadas de 1960 e 1970: diálogos entre religião e política. Recife: Ed. UFPE, 2015.

\section{Fontes Consultadas}

JUSTIÇA DO TRABALHO / JUNTA DE CONCILIAÇÃO E JULGAMENTO DO PAULISTA. Processo Trabalhista da Junta de Conciliação e Julgamento do Paulista, $n^{o}$ 0631/65. (Acervo do Arquivo do TRT/UFPE). 